\title{
Literatura e arte propondo encontros com o fora à educação
}

Literature and art proposing encounters with the outside to education

Elaine Schmidlin

Universidade do Estado de Santa Catarina

\section{Resumo}

O texto problematiza a literatura e a arte como experiência que provoca uma ruptura e/ou deslocamento em relação à estrutura comum da linguagem. Por entre a prosa/poesia de Ana Cristina Cesar, surge o desconhecido, a outra noite, o lado de fora da literatura, como a entende Maurice Blanchot. Por outro lado, para Gilles Deleuze, essa noção é o que leva o pensamento a criar, tanto na filosofia quanto na arte. Com os autores, a escrita percorre esses campos, abrindo-se ao fora, ou seja, a uma prática sempre em vias de se fazer, no sentido de propor à educação modos de resistir ao que a aprisiona, para deixar vir à superfície a criação em seu murmúrio incessante.

Palavras-chave: Educação, Arte, Filosofia, Literatura, Fora.

\begin{abstract}
The text discusses literature and art as an experience that causes a rupture and / or displacement in relation to the usual structure of language. In between the prose/poetry of Ana Cristina Cesar, arises the unknown, the other night, the outside of literature, as understood by Maurice Blanchot. On the other hand, for Gilles Deleuze, it is this notion that leads the thought to create, both in philosophy and in art. With these authors, the present writing goes through these fields, opening itself to the outside, that is, to a practice that is always in process of doing itself, in the sense that it proposes to education, ways to resist to what imprisons it, in order to let creation come to the surface in its own incessant murmuring.
\end{abstract}

Keywords: Education, Art, Philosophy, Literature, Outside.

A teus pés

Eu tenho uma ideia. Eu não tenho a menor ideia. Uma frase em cada linha. Um golpe de exercício.

Propor encontros com o fora à educação exige percorrer uma escrita em atravessamento com a literatura, a filosofia e a arte. Inicialmente, levada pela força da prosa/poesia de Ana Cristina Cesar, escrevo em uma experiência com o fora que, como diz Blanchot, é noturna, aquela própria da outra noite em que tudo que desapareceu aparece. Movimento

\footnotetext{
1 Ana Cristina Cesar (1952 - 1983), nasceu no Rio de Janeiro, foi poeta, jornalista, tradutora e crítica literária. Fonte: CESAR, 2013
}

Revista Digital do LAV - Santa Maria - vol. 10, n. 2, p. 190 - 199 - mai./ago. 2017 ISSN 1983 - 7348 http://dx.doi.org/10.5902/1983734827053 
próprio da literatura, em que escrever é algo incessante e sem intimidade, que independe daquele que escreve. Nessa outra noite "estamos sempre do lado de fora, numa morte que não morre, num esquecimento que não esquece, num tempo que se repete e nunca acaba" (PELBART, 2009, p.71).

Nesse lugar que é um não lugar, em que "palavras escorrem como líquidos lubrificando passagens ressentidas", apenas vou teclando "uma frase em cada linha" (CESAR, 2013, p.198). Com a literatura, procuro escavar passagens por entre a filosofia e a arte, abrindo suas margens a essa outra noite desconhecida, lugar do fora, noção central no pensamento de Blanchot, que marca a ruptura na literatura com o logos clássico, "colocando em xeque noções centrais para a filosofia e a teoria literária, como as noções de autor, linguagem, experiência, realidade e pensamento" (LEVY, 2011, p.12).

Com os pés no fora, assim me encontro. "Esta é a minha vida" (CESAR, 2013, p.77), alguém disse. "Autobiografia. Não, biografia" (idem). Porém, escrever não é impor uma forma a algo vivido, mas uma passagem de Vida, diria Deleuze. Com ele, Blanchot e Ana Cesar, escrevo em uma zona de vizinhança, aproximando-me e apresentando um lugar de uma relação disjunta entre filosofia, arte e educação. Talvez, como quem faz arte ou literatura, que busca devires alcançando os desvios moleculares da língua em sua expressão, para trazer à tona a potência de um impessoal, "não como uma generalidade, mas como uma singularidade no mais alto grau: um homem, uma mulher, um animal, um ventre, uma criança..." (DELEUZE, 2011, p.13).

Por [entre] as palavras, a literatura

Na coletânea póstuma Poética, com curadoria editorial de Armando Freitas Filho, apresenta-se uma compilação dos livros de Ana Cristina Cesar, alguns editados durante as décadas de 70 e 80. Nessa editoração, Ana Cristina Cesar ou apenas Ana C. como costumava referenciar-se, apresenta em suas prosas/poesias alguns microacontecimentos cotidianos (conversas ao telefone, diários, cartas, entre outros) que se passam sempre em uma esfera molecular, reinventando-os e endereçando-os a um leitor impessoal, pois anônimo e singular. Nesse endereçamento, a alteridade se instala atravessada (ou não) por um ato de (re)conhecimento.

Nesse atravessamento entre a ficção e o real, a palavra literária de Ana inventa um mundo concreto que se realiza, ou se concretiza, a partir de si mesmo. Para Blanchot, a literatura constitui essa "experiência que, ilusória ou não, aparece como meio de descoberta e de um esforço, não para expressar o que sabemos, mas para sentir o que não sabemos" (2011 (a), p. 87). Por isso, a linguagem ficcional da literatura propõe um contato com a narrativa irreal da obra literária que, em vez de representar o mundo, apresenta "o outro de todos os mundos", como diz Blanchot. As situações e/ou personagens apresentados são

Revista Digital do LAV - Santa Maria - vol. 10, n. 2, p. 190 - 199 - mai./ago. 2017 ISSN 1983 - 7348 http://dx.doi.org/10.5902/1983734827053 
sensações que nos fazem sentir e, portanto, tornam-se plenamente real. A palavra literária chama o leitor a viver o que lhe é proposto, enquanto a linguagem comum, ao dizer as coisas, somente estabelece uma ligação entre o objeto e aquele que o lê, em seu valor prático e funcional. Diferentemente, a palavra literária inventa um mundo e/ou cria objetos e coisas irreais transpondo-as à realidade da linguagem. Para tanto, nega o real para constituir a (ir)realidade fictícia da literatura, fazendo emergir na superfície a palavra da poesia.

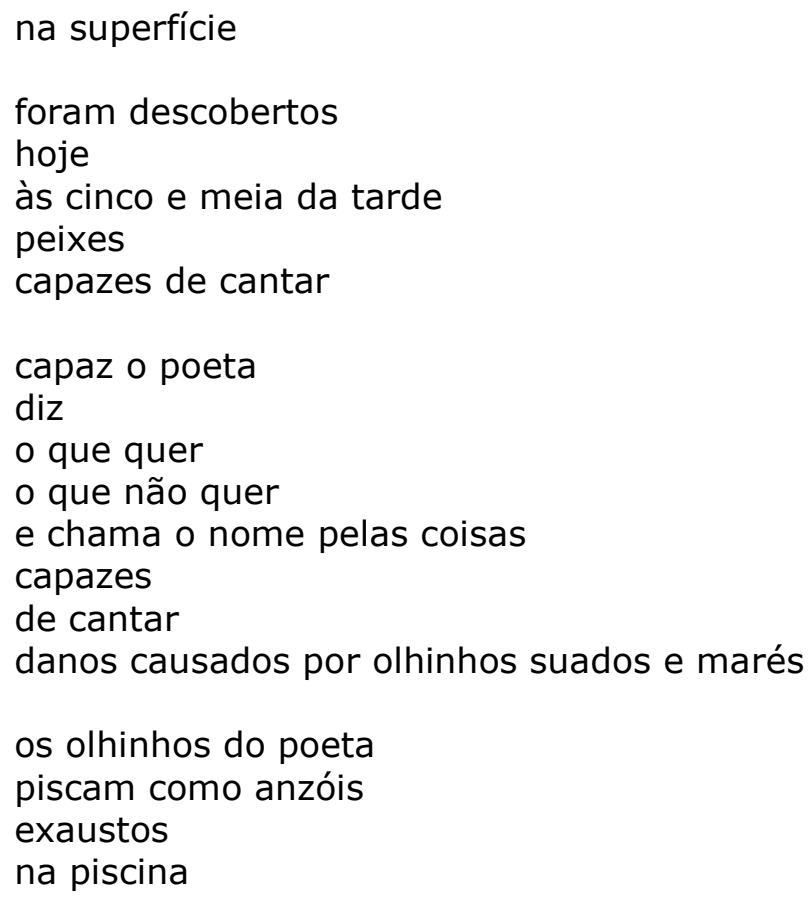

Ana Cristina Cesar

Levy (2011) comenta que, na literatura, o ato de nomear é antes "um assassinato diferido", um gesto de negação do real, de modo a refletir o não ser do mundo realizando-se em sua própria falta, como também o faz Ana Cesar. Nesse jogo, a falta se situa no movimento próprio da literatura, em que aquilo que é nomeado desaparece para tornar-se outra realidade, fazendo de uma presença uma não presença, ou seja, a ruína da realidade é o que revela a presença desse desaparecimento. Sobre essa questão, Pelbart comenta que a obra só se torna obra quando se desobra, ou seja, "a obra na sua dimensão mais própria, é desobramento. A dificuldade desta ideia está no paradoxo de que o desobramento, que é o oposto da obra, também é, e ao mesmo tempo, sua essência mais íntima" (2009, p.71).

Essa ambiguidade é a característica da linguagem literária, pelo fato de fazer as coisas desaparecerem e, ao mesmo tempo, revelar a presença desse desaparecimento. 
A literatura aprende que não pode ultrapassar-se em direção ao seu próprio fim: ela se esquiva e não se trai. Sabe que é esse movimento pelo qual, continuamente, o que desaparece aparece. Quando nomeia, o que ela designa é suprimido; mas o que é suprimido é mantido, e a coisa encontrou (no ser que é a palavra) mais um refúgio do que uma ameaça. (BLANCHOT, 2011(a), p. 337).

Movimento da literatura, que é seu próprio fora, em que a palavra age com sua força tornando-a linguagem presente fora dela mesma. Então, essa linguagem torna-se coisa como salienta Blanchot: "é a coisa escrita, um pedaço de casca, uma lasca de rocha, um fragmento de argila em que subsiste a realidade da terra" (2011(a), p. 138). Ao tornar-se coisa, a linguagem também exige sua existência sem o autor, dispensando-o. Desse modo, escrever torna-se um processo interminável em que aquele que escreve também desaparece no murmúrio incessante das palavras.

[...] O que fala nele é uma decorrência do fato de que de uma maneira ou de outra, já não é ele mesmo, já não é ninguém. O "Ele" que toma o lugar do "Eu", eis a solidão que sobrevém ao escritor por intermédio da obra. "Ele" não designa o desinteresse objetivo, o desprendimento criador. [...] "Ele" sou eu convertido em ninguém, outrem que se torna o outro, é que, do lugar onde estou, não possa mais dirigir-me a mim e que aquele que se me dirige não diga "Eu", não seja ele mesmo. (BLANCHOT, 2011(b), p.19).

Nessa experiência que se desdobra para fora do mundo, a literatura dispensa o escritor, não sendo mais o ideal de uma consciência que ilumina o mundo em uma perspectiva representativa como espelho do mundo. Porém, cabe salientar que essa experiência "não está além do mundo mas também não é o mundo" (BLANCHOT, 2011 (a), p. 336). É, no entanto, somente aquilo que aparece quando tudo desapareceu, momento em que a literatura se propõe a dizer: "Não represento mais, sou; não significo, apresento." (Idem, p. 337).

Por entre as palavras, a narrativa literária escorre para o vazio de onde veio, sua origem, abandonando o pensamento de uma subjetividade interior, deixando vir à superfície sua exterioridade mais profunda. Nessa relação, a interioridade foi atraída pelo fora, sem intimidade, sem segredo, retirando do autor o poder de dizer "eu". Surge, então, uma espécie de anonimato informe do espaço literário, seu exílio num deserto onde nada se fixa, em que as palavras estão sempre suspensas numa espécie de tremor que as deixa desenrolarem-se infinitamente pela superfície.

"Na experiência do fora, portanto, o eu não se reconhece mais, uma vez que cede lugar à impessoalidade do ele" (LEVY, 2011, p.49). É por essa impessoalidade que a literatura transita da intimidade do relato de um eu à neutralidade de um ele em sua singularidade, sempre em devir. Para Deleuze, "a escrita é inseparável do devir: ao escrever, estamos 
num devir-mulher, num devir-animal ou vegetal, num devir-molécula, até num devirimperceptível" (DELEUZE, 2011, p.11). Com Ana, em devir, aprendo que:

atrás dos olhos das meninas sérias

Aviso que vou virando um avião. Cigana do horário nobre do adultério. Separatista protestante. Melindrosa basca com fissura da verdade. Me entenda faz favor: minha fraqueza era meu fraco, o primeiro sidecar anfíbio nos classificados de aluguel. [...]

Ana Cristina Cesar

Por [entre] filosofia e arte

Em Deleuze, a noção do fora aparece como lugar de forças selvagens ${ }^{2}$, presentes no movimento do pensar, tanto na filosofia quanto na arte. "Fazer do pensamento e da arte uma experiência do fora pressupõe o contato com uma violência que nos tira do campo da recognição e nos lança diante do acaso, onde nada é previsível, [...]" (LEVY, 2011, p. 100). Pensar, para Deleuze e Guattari, está no plano de imanência que "não é um conceito pensado nem pensável, mas a imagem do pensamento, a imagem do que ele se dá a pensar [...]" (2004, p. 53). Portanto, esse plano não pertence a um sujeito ou a um mundo transcendente, pois é o mundo (nosso mundo), ou ainda, o outro de todos os mundos, retomando Blanchot.

É quando a imanência não mais é imanente a outra coisa senão a si que se pode falar de um plano de imanência. Um tal plano é, talvez, um empirismo radical: ele não apresenta um fluxo do vivido imanente a um sujeito, e que se individualiza no que pertence a um eu. Ele não apresenta senão acontecimentos, isto é, mundos possíveis enquanto conceitos, e outrem, como expressões de mundos possíveis ou personagens conceituais. O acontecimento não remete o vivido a um sujeito transcendente $=\mathrm{Eu}$, mas remete, ao contrário, ao sobrevoo imanente de um campo sem sujeito. (DELEUZE e GUATTARI, 2004, p. 65-66).

Assim, a imanência constitui um fora absoluto em que nada se esconde em seu interior formado por singularidades selvagens, que não são individuais ou referidas a um sujeito. Composto por essas singularidades neutras, o plano não tem forma nem substância, e pensar já não é mais uma reflexão nem uma vontade de encontrar a verdade como aquela do logos clássico. "O primeiro caráter da imagem moderna do pensamento é talvez o de

\footnotetext{
2 Em sua leitura sobre o poder em Foucault, Deleuze $(2005$, p.78) comenta que a força não está nunca no singular, ela tem como característica essencial estar em relação com outras forças, de forma que toda força já é relação, isto é, poder: a força não tem objeto nem sujeito, a não ser a força.
}

Revista Digital do LAV - Santa Maria - vol. 10, n. 2, p. 190 - 199 - mai./ago. 2017 ISSN 1983 - 7348 http://dx.doi.org/10.5902/1983734827053 
renunciar completamente a esta relação, para considerar que a verdade é somente o que o pensamento cria [...]" (Idem, p. 73).

Nessa perspectiva, pensar é criar, porém, de um modo que nos retira do senso comum e nos lança ao desconhecido, a um fora, em que forças rompem com as verdades e certezas já constituídas. Pensar, então, torna-se algo que ocorre por uma intrusão ou abalo no pensamento e não mais como uma atividade inata de um sujeito. Desse modo, como sugere Levy, o processo de criação, tanto filosófico quanto artístico, "quando engendrado com a experiência daquilo que se chama o fora, promove o surgimento de uma nova ética, de uma nova maneira de se relacionar com o real" (LEVY, 2011, p. 100). Nesse movimento, a literatura e a arte, ao promover o encontro com o fora, também nos confrontam com 0 intolerável presente no mundo. Como gesto político, elas podem nos possibilitar acreditar de novo na vida e no mundo, acreditar nisso, como no impossível e no impensável.

Nesse campo de forças, sem formas, a imanência é o plano da formação criadora da vida, movimento do infinito, que não se prende à intencionalidade de um sujeito nem a um objeto. É essa vida que atravessa a escrita, o ato de criação, pois "escrever é um caso de devir, sempre inacabado, sempre em vias de fazer-se, e que extravasa qualquer matéria vivível ou vivida" (DELEUZE, 2011, p.11).

conversa de senhoras

$[\ldots]$

Ele dança que nem um realejo

Escritor não existe mais

Mas também não precisa virar deus

Tem alguém na casa

Você acha que ele aguenta?

$[\ldots]$

Ana Cristina Cesar

Escrever na imanência, como o faz Ana Cesar, é deixar que as palavras revertam à interioridade de um eu, para emergir em sua exterioridade nesse plano sensível em que imagens e sensações circulam. Ao agir na imanência, a literatura e a arte provocam sensações extremamente reais e tornam novamente pensável o impensado de todo pensamento. A linguagem, nesse processo, é levada ao seu limite, a um fora, que consiste em visões e audições que não pertencem a língua alguma. Como salienta Deleuze, "essas visões não são fantasmas, mas verdadeiras Ideias que o escritor vê e ouve nos interstícios da linguagem, nos desvios da linguagem." (2011, p.16). Nos desvios, entre imagens e coisas, a escrita escava as palavras para revelar a vida nas coisas.

vacilo da vocação

Precisaria trabalhar - afundar -

Revista Digital do LAV - Santa Maria - vol. 10, n. 2, p. 190 - 199 - mai./ago. 2017 ISSN 1983 - 7348 http://dx.doi.org/10.5902/1983734827053 
- como você - saudades loucas -

nesta arte - ininterrupta -

de pintar -

A poesia não - telegráfica - ocasional -

me deixa sola - solta -

à mercê do impossível -

- do real.

Ana Cristina Cesar

Por [entre] formas e forças, o fora

Em Blanchot, ir ao encontro do fora seria o movimento da própria literatura, quando aquele que escreve desaparece para dar lugar ao neutro. Em Deleuze, esse fora é constituído por forças capazes de abalar o pensamento, questionando certezas e verdades do senso comum. Por outro lado, Ana Cristina Cesar escreve atravessada por acontecimentos e singularidades no campo de imanência em que a vida circula em sua plena potência, abandonando representações e refinando as convenções formais da linguagem literária.

Quando a literatura e a arte alcançam a experiência do fora, mostram-nos novos modos de existir, que escapam ao que nos aprisiona. Ao inventá-los, fazem um apelo a um povo que falta, como salienta Deleuze, pois a realidade, a terra, o povo, não necessita ser representada, mas inventada. Então, resistir é devir, é tornar-se nômade, exilado e errante, um estrangeiro e um estranho à sua própria cultura.

A saúde como literatura, como escrita, consiste em inventar um povo que falta. Compete à função fabuladora inventar um povo. Não se escreve com as próprias lembranças, a menos que delas se faça a origem ou a destinação coletiva de um povo por vir ainda enterrado em suas traições e renegações.

(DELEUZE, 2011, p. 14).

Enquanto a literatura e a arte se compõe a partir do encontro com forças informes, a educação se organiza em torno de formas do saber, compostas pelo agenciamento entre enunciados e visibilidades que se articulam em cada época histórica (DELEUZE, 2005, p.57). Porém, se o saber é uma combinação do que se pode ver e falar em um determinado período, os enunciados jamais nos fazem ver alguma coisa, assim como as visibilidades jamais tornam algo legível, afirma Foucault em As palavras e as coisas. O que pode ser dito e visto em um período nunca está oculto, pois está sempre na superfície inscrita em uma relação sem relação, em que a diferença prevalece. Enquanto o saber é feito de enunciados e visibilidades, ou seja, de formas que compõem os estratos (a história), o poder é constituído de forças móveis, informes, que compõem o diagrama (campo da virtualidade). Por não ter forma, o poder é difuso e se encontra em todos os lugares, 
funcionando como uma rede em que nada escapa. O poder, então, é o elemento informal que atravessa as formas do saber, em que forças virtuais se atualizam, isto é, ganham formas no plano dos estratos. Desse modo, saber e poder estão interligados, contudo, se por um lado os diagramas são compostos por relações de forças que se encontram em perpétuo devir, "por outro, estão sempre presos no complexo poder-saber, enquanto que a linha do fora, por sua vez, se coloca à margem desse complexo" (LEVY, 2011, p. 83). Cabe salientar, que o fora é o território do devir, do informe ou sem forma, das forças e singularidades nômades, no qual as coisas não são ainda e, portanto, não pode ser confundido com o diagrama.

Enquanto a educação circula pelo complexo poder-saber, a literatura e a arte transitam por esse fora ou, como diz Deleuze, cavalgam as linhas do fora a cada vez que pensam com suficiente vertigem, ou quando vivem com bastante força, como o fez Ana Cesar. Essa linha do fora, que não é mais uma relação de poder, também não é uma linha abstrata, embora não forme nenhum contorno. Essa linha está em toda parte em que pensar enfrenta algo como a loucura e a vida, algo como a morte. Pode ser a linha de um pintor ou "aquela que mata Van Gogh. O pensamento vem desse fora e a ele retorna, cabe ao pensamento enfrentá-lo" (2004, p.136-137).

Pensar, desse ponto de vista, é resistir ao que nos aprisiona, é ir ao encontro de forças que carregam o que está fixo e imóvel, propondo-nos pensar de outro modo, em direção a um futuro a-histórico, inaugurando novas possibilidades éticas e estéticas de vida. Para tanto, é preciso, como afirma Deleuze:

Pensar o passado contra o presente, resistir ao presente, não para um retorno, mas "em favor, espero de um tempo que virá" (Nietzsche), isto é, tornando o passado ativo e presente fora, para que surja enfim algo novo, para que pensar, sempre, suceda o pensamento. O pensamento pensa sua própria história (passado), mas para ele se libertar do ele pensa (presente) e poder, enfim, "pensar de outra forma" (futuro). É o que Blanchot chamava "a paixão do lado de fora", uma força que só tende em direção ao fora porque o próprio fora tornou-se a "intimidade", a "intrusão". (DELEUZE, 2005, p.127).

O que posso propor à educação a partir desta escrita, senão o seu movimento para o fora, capaz de desorganizar os seus controles, suas reformas, pois "tentam nos fazer acreditar numa reforma da escola, quando se trata de uma liquidação. Num regime de controle nunca se termina nada" (DELEUZE, 2006, p.216).

Como forma de saber, a educação, em seus enunciados, nada diz sobre a escola, que é a sua visibilidade. Políticas públicas, novas reformas do ensino médio e fundamental, e assim por diante, constituem com a escola uma relação sem relação, em que as forças estão sempre presas em seu complexo poder-saber. Como, então, resistir ao que insiste em nos 
modelar? Como deixar emergir à superfície uma educação que leve em conta a vida em sua potência? O que precisamos para acreditar de novo na educação? Para Deleuze, "precisamos de uma ética ou de uma fé, o que faz os idiotas rirem; não é uma necessidade de crer em outra coisa, mas uma necessidade de crer neste mundo, do qual fazem parte os idiotas" (Idem, p.209).

Cabe à educação, aprender com a literatura e a arte a experiência que, como pensamento da criação, resiste ao que se coloca no mundo como verdade. Como faz Ana Cesar, que traz os acontecimentos cotidianos inventados como se estivesse em um exílio estrangeiro, fato que a faz deslizar incessantemente sobre a linguagem. Quase como se, ao escrever, Ana estivesse em um território indefinido, não pertencente a lugar nenhum e, ao fazê-lo, circunscrevesse novos territórios na literatura, clamando àquele povo por vir.

A educação necessita abrir mão de sua interioridade em prol de um povo, saindo de seu território e se colocando no mundo para, então, fazer uma revolução que tenha um valor coletivo. Talvez, como Ana Cesar, inventar a poesia de um povo por vir na educação, criando jardins informes em pedaços de vida, com um céu que recua, sem pergunta, ausência frequentada sem mistério em uma falta contemplada.

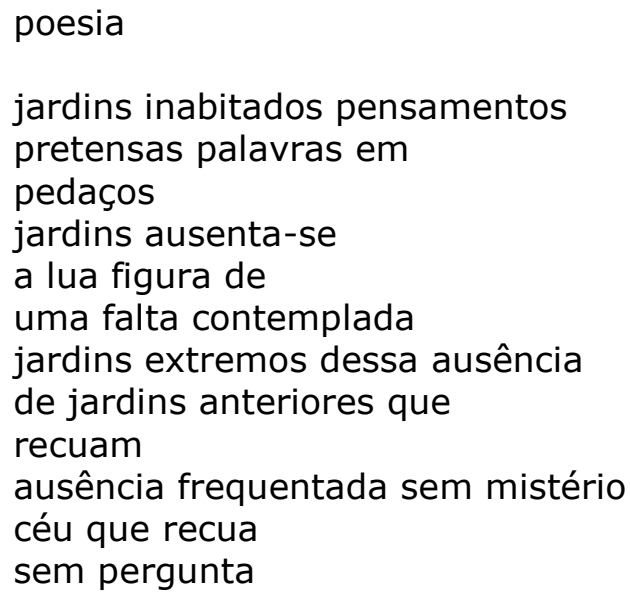

Ana Cristina Cesar

Como a literatura, a educação pode abandonar o pensamento profundo de sua interioridade, promovendo um trânsito ao fora, revelando, não mais formas, mas apenas o murmúrio incessante da criação. Para tanto, a educação precisa negar seus próprios discursos, como faz Blanchot, deixá-los atrás de si para estar livre a um começo que possa explodir à superfície. O mais profundo é a pele, afirma Valéry, e Deleuze responde: "Sim, é uma linda fórmula. Os dermatologistas deveriam inscrevê-la em sua porta [...] a superfície não se opõe à profundidade [...], mas à interpretação" (2006, p. 109). A seguir, comenta sobre Foucault e salienta que ele sempre se contrapôs aos métodos de 
interpretação. E diz: "Jamais interprete, experimente..." (Idem). A fórmula da interpretação ainda é uma ação muito presente nos fazeres educacionais, contrapondo-se, muitas vezes, à experimentação. Na escola, experimenta-se pouco e interpreta-se muito. Talvez, seja preciso experimentar outra educação, que a leve ao encontro de forças, aos acasos, que podem inventar outros modos estéticos de vivê-la, operando o movimento próprio do nômade, sempre em vias de se fazer, algo que pode estar, simplesmente, $a$ teus pés.

\section{Referências}

BLANCHOT, Maurice. A parte do fogo. Tradução de Ana Maria Scherer. Rio de Janeiro: Rocco, 2011 (a).

O espaço literário. Tradução de Álvaro Cabral. Rio de Janeiro:

Rocco, 2011 (b).

CESAR, Ana Cristina. Poética. $1^{a}$ ed. São Paulo: Companhia das Letras, 2013.

DELEUZE, Gilles. Conversações. $5^{a}$ ed. Tradução de Peter Pál Pelbart. São Paulo: Ed. 34, 2006.

Brasiliense, 2005.

Foucault. Tradução de Claudia Sant' Anna Martins. São Paulo: Crítica e Clínica. $2^{a}$ ed. Tradução de Peter Pál Pelbart. São Paulo: Ed. $34,2011$. GUATTARI, Félix. 0 que é a filosofia. $2^{a}$ ed. Tradução de Bento Prado Júnior e Alberto Alonso Muñoz. Rio de Janeiro: Ed. 34, 2004.

LEVY, Tatiana. A experiência do fora: Blanchot, Foucault e Deleuze. Rio de Janeiro: Civilização Brasileira, 2011.

PELBART, Peter Pál. Da clausura do fora ao fora da clausura: loucura e desrazão. $2^{a}$ ed. São Paulo: Iluminuras, 2009.

\footnotetext{
i Professora do Programa de Pós-Graduação em Artes Visuais do Centro de Artes da Universidade do Estado de Santa Catarina (CEART/UDESC) e vice-líder do Grupo de Pesquisa [entre]paisagens CNPq/UDESC
}

Enviado em: 08 de maio de 2017.

Aprovado em: 17 de agosto de 2017. 